$06.1 ; 06.5$

\title{
Функционализация многостенных углеродных нанотрубок ионным пучком для повышения межфазной адгезии в композитах с оксидом олова
}

\author{
(C) С.Н. Несов ${ }^{1}$, П.М. Корусенко ${ }^{1}$, В.В. Болотов ${ }^{1}$, К.Е. Ивлев ${ }^{1}$, Е.В. Черников ${ }^{2}$, С.Н. Поворознюк ${ }^{1}$ \\ ${ }^{1}$ Омский научный центр СО РАН, Омск, Россия \\ 2 Национальный исследовательский Томский государственный университет, Томск, Россия \\ E-mail: nesov55@mail.ru
}

Поступило в Редакцию 17 апреля 2020г.

В окончательной редакции 27 апреля 2020г.

Принято к публикации 27 апреля 2020г.

Методами сканирующей электронной микроскопии, а также рентгеновской спектроскопии исследовано влияние обработки многостенных углеродных нанотрубок (МУНТ) пучком ионов аргона на структуру композитов $\mathrm{SnO}_{x} / \mathrm{MУHT,} \mathrm{формируемых} \mathrm{методом} \mathrm{магнетронного} \mathrm{распыления.} \mathrm{Показано,} \mathrm{что} \mathrm{применение}$ ионной обработки повышает межфазную адгезию и позволяет формировать композиты с равномерным распределением оксида олова по поверхности углеродных нанотрубок в виде сплошных слоев, обладающих однородной структурой.

Ключевые слова: многостенные углеродные нанотрубки, оксид олова, композит, ионное облучение, магнетронное распыление.

DOI: 10.21883/PJTF.2020.15.49744.18343

Массивы многостенных углеродных нанотрубок (МУНТ), декорированных слоями или наночастицами оксида олова (композиты $\mathrm{SnO}_{x} / \mathrm{MУНТ),} \mathrm{являются}$ перспективным материалом для изготовления анодов литий-ионных аккумуляторов и чувствительных элементов газовых сенсоров [1,2]. Массивы МУНТ выступают в качестве электропроводящей основы композита, обладающей большой удельной площадью поверхности. Однако химическая инертность углеродных нанотрубок не обеспечивает достаточной адгезии оксида металла к их поверхности. Это приводит к неравномерному распределению металлооксидного компонента по поверхности МУНТ и не позволяет обеспечить стабильные характеристики получаемых композитов. Традиционно для повышения химической активности МУНТ применяют методы функционализации, основанные на обработке в среде различных окислителей [3,4]. Целью проведения таких обработок является формирование структурных дефектов и функциональных групп на поверхности МУНТ, выступающих в качестве активных центров закрепления оксида металла при дальнейшем формировании композитов. В настоящей работе в качестве метода функционализации поверхности МУНТ предлагается использовать облучение ионным пучком.

Для формирования композитов $\mathrm{SnO}_{x}$ /МУНТ в работе использовались массивы МУНТ, синтезированные методом CVD (chemical vapor deposition) путем пиролиза смеси ацетонитрила с ферроценом (100:2) на кремниевых подложках. В одном цикле синтеза были получены два массива МУНТ, один из которых затем подвергался обработке непрерывным пучком ионов $\mathrm{Ar}^{+}$со средней энергией $5 \mathrm{keV}$ и флюенсом $\sim 5 \cdot 10^{16} \mathrm{~cm}^{-2}$. Облуче- ние проводилось с использованием ускорителя газометаллических ионных пучков (ОНЦ СО РАН, Омск). Осаждение оксида олова на поверхность исходного и облученного массивов МУНТ осуществлялось методом магнетронного распыления с применением магнетрона A-500 Edwards (ТГУ, Томск). Мишень $\mathrm{SnO}_{2}$ распылялась в аргоно-кислородной плазме при постоянном токе. Рабочее давление в камере магнетрона составляло $8.5 \cdot 10^{-3} \mathrm{mbar}$, мощность разряда $70 \mathrm{~W}$, температура подложки $20^{\circ} \mathrm{C}$. Концентрация кислорода в смеси $\mathrm{Ar}+\mathrm{O}_{2}$ поддерживалась на уровне $56.1 \pm 0.5 \mathrm{vol} . \%$. Расстояние между мишенью и подложкой составляло $70 \mathrm{~mm}$.

В работе [5] с применением комплекса экспериментальных методов исследования было детально изучено изменение структурно-химического состояния МУНТ под влиянием облучения пучком ионов $\mathrm{Ar}^{+}$. Было показано, что вследствие облучения на поверхности МУНТ формируются мультивакансионные структурные дефекты. Это в свою очередь приводит к закреплению функциональных кислородсодержащих групп различного типа: гидроксидных, фенольных, эпоксидных, карбоксильных, карбонильных, карбонатных.

Анализ полученных методом сканирующей электронной микроскопии (СЭМ) изображений композита, сформированного на исходном массиве МУНТ (рис. 1, $a, b$ ), показывает неравномерность распределения оксида олова по поверхности углеродных нанотрубок. На поверхности МУНТ наблюдается наличие оксида олова как в виде неравномерного по толщине слоя, так и в виде крупных глобул и их агломератов, размеры которых достигают $\sim 200-300 \mathrm{~nm}$. В композите, сформирован- 

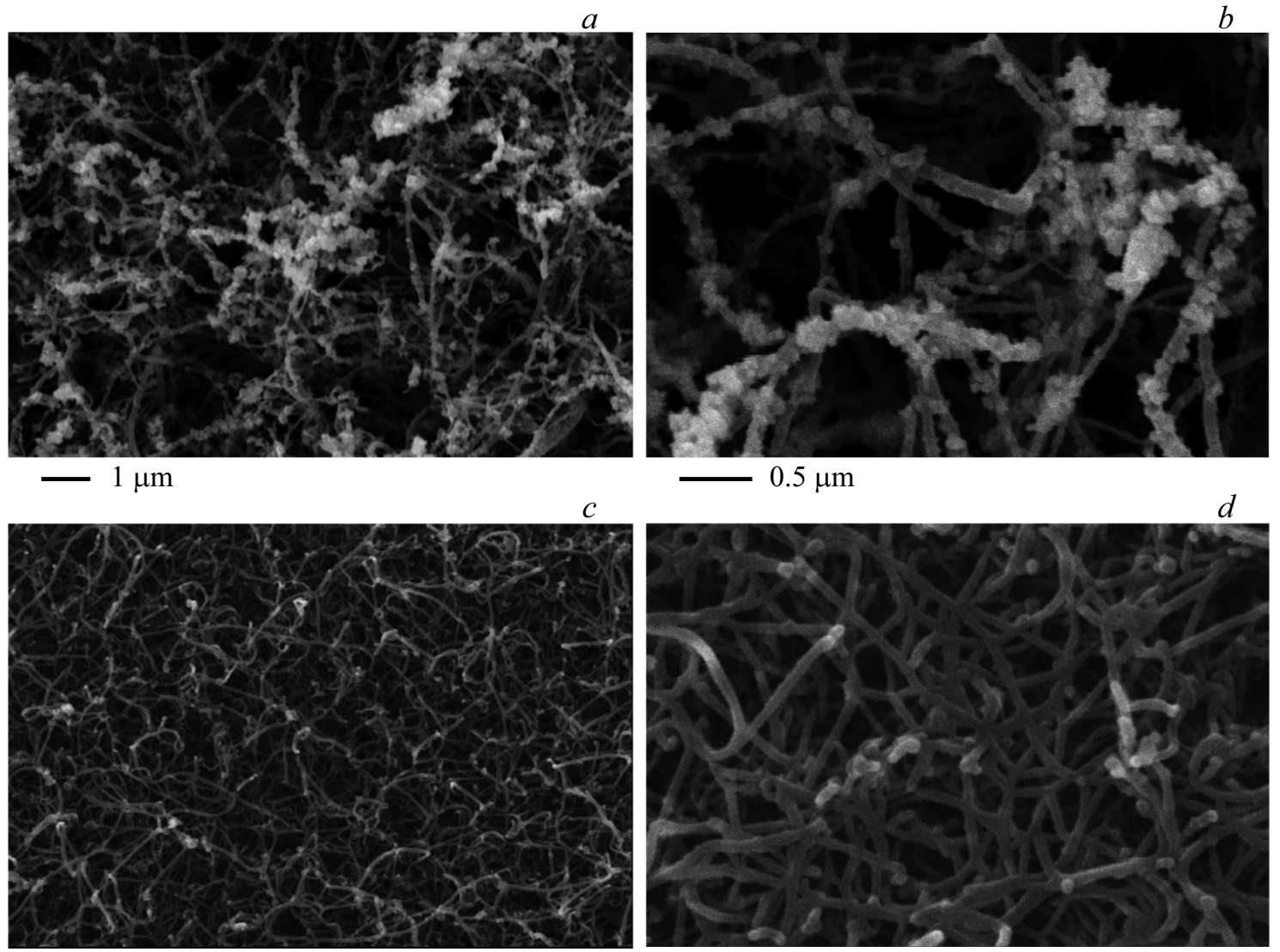

$-1 \mu \mathrm{m}$

$0.5 \mu \mathrm{m}$

Рис. 1. СЭМ-изображения (с различным увеличением) композитов $\mathrm{SnO}_{x} / \mathrm{MУНТ,} \mathrm{сформированных} \mathrm{на} \mathrm{исходном} \mathrm{(a,} b$ ) и облученном $(c, d)$ массивах МУНТ.

ном на облученном массиве МУНТ (рис. $1, c, d)$, оксид олова распределяется по поверхности углеродных нанотрубок в виде сплошного слоя одинаковой толщины. При этом полностью отсутствуют кластеры оксида олова и их агломераты. Различия структуры и морфологии композитов указывают на более высокую адгезию оксида олова к поверхности предварительно облученных МУНТ. Поверхность облученных МУНТ содержит больше структурных дефектов, что повышает количество мест для закрепления оксида металла за счет более развитой поверхности. Кроме того, функциональные группы, присутствующие на поверхности облученных МУНТ, увеличивают вероятность закрепления оксида олова за счет электростатического и ковалентного взаимодействия с ними [6,7]. Формирование сплошных и однородных слоев оксида олова может указывать на равномерность воздействия ионного пучка по площади массива МУНТ в процессе облучения.

На рис. 2 представлены обзорные рентгенофотоэлектронные спектры (РФЭС) сформированных композитов $\mathrm{SnO}_{x}$ /МУНТ. Спектры измерены с использованием немонохроматического $\mathrm{A} 1 K_{\alpha}$-излучения. Глубина анализа составляет $\sim 3-5 \mathrm{~nm}$. В спектрах присутствуют РФЭС-линии олова $(\operatorname{Sn} 3 p, 3 d, 4 s, 4 p, 4 d)$, кислорода (О 1s) и

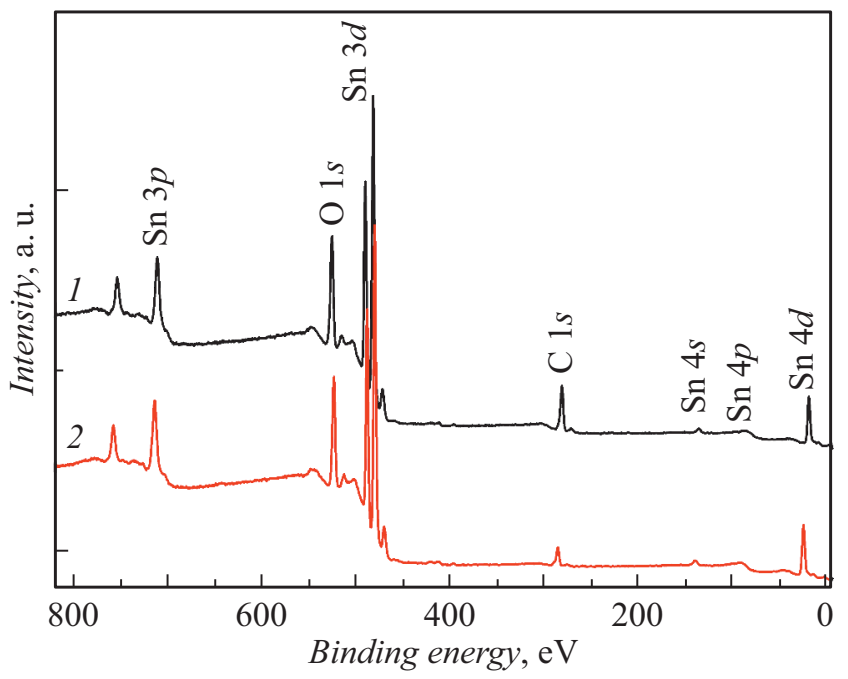

Рис. 2. Обзорные РФЭС композитов $\mathrm{SnO}_{x} / \mathrm{MУНТ,} \mathrm{сформиро-}$ ванных на исходных (1) и облученных (2) МУНТ.

углерода (C $1 s)$. Результаты количественного анализа обзорных РФЭС с применением метода коэффициентов элементной чувствительности представлены в таблице. 
Состав поверхности композитов $\mathrm{SnO}_{x}$ /МУНТ, сформированных на исходном и облученном массивах МУНТ (по данным РФЭС)

\begin{tabular}{c|c|c|c}
\hline \multirow{2}{*}{ Массив МУНТ } & \multicolumn{3}{|c}{ Концентрация, at. \% } \\
\cline { 2 - 4 } & {$[\mathrm{C}]$} & {$[\mathrm{O}]$} & {$[\mathrm{Sn}]$} \\
\hline Исходный & 42.1 & 40.2 & 17.7 \\
Облученный & 24.0 & 51.2 & 24.8
\end{tabular}

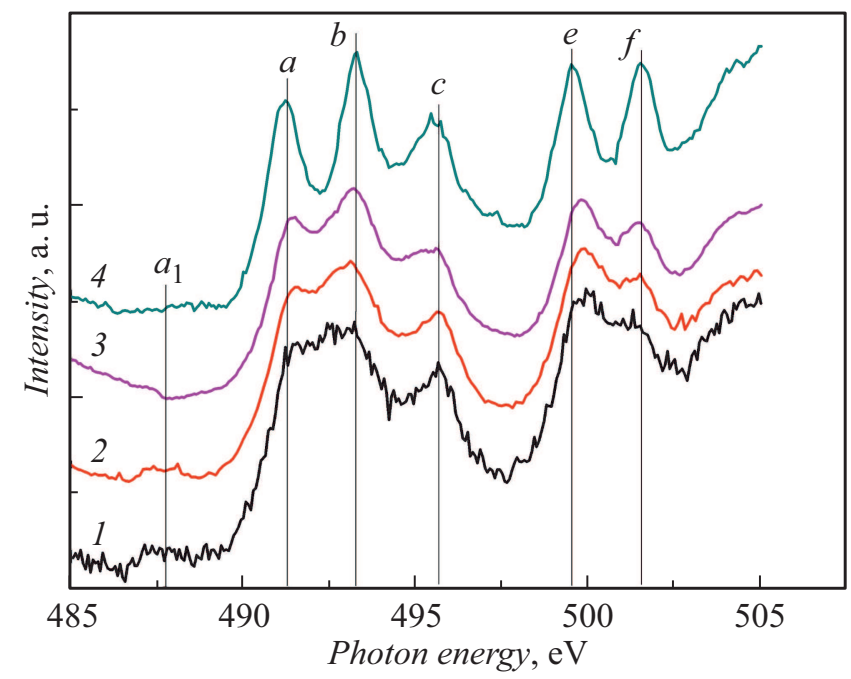

Рис. 3. NEXAFS Sn $M_{5,4}$-спектры композитов $\mathrm{SnO}_{x} / \mathrm{MУHT}$, сформированных на исходных (1) и облученных (2) МУНТ, а также порошков кристаллических оксидов олова $\mathrm{SnO}(3)$ и $\mathrm{SnO}_{2}(4)$.

Более высокая концентрация углерода в поверхностном слое композита, сформированного на исходном массиве МУНТ, очевидно, обусловлена недостаточной сплошностью слоя оксида олова, покрывающего углеродные нанотрубки. Анализ РФЭС дублетной линии олова Sn $3 d$ для композитов (не приводятся на рисунках) показал, что положения максимумов $\mathrm{Sn} 3 d_{5 / 2}$ и $\mathrm{Sn} 3 d_{3 / 2}$ в них практически совпадают и составляют 487.1 и $495.7 \mathrm{eV}$ соответственно, что отвечает оксиду $\mathrm{SnO}_{2}$ [8]. Однако с учетом глубины анализа метода РФЭС однозначный вывод о химическом состоянии олова в композитах сделать нельзя ввиду значительного вклада в спектр сигнала от поверхностного оксида, сформированного при хранении композитов на воздухе.

Дополнительно локальная атомная структура и химическое состояние оксида олова в композитах исследовались с помощью метода NEXAFS (near edge $X$-ray absorption fine structure), реализованного с применением синхротронного излучения накопительного кольца BESSY II (Берлин, Германия). Спектры были зарегистрированы в режиме измерения тока утечки с образца. Глубина анализа методом NEXAFS в данном режиме составляет $\sim 20 \mathrm{~nm}$. На рис. 3 представлены NEXAFS-спектры Sn $M_{5,4}$-края поглощения композитов
$\mathrm{SnO}_{x} / \mathrm{MУНТ,} \mathrm{сформированных} \mathrm{на} \mathrm{исходном} \mathrm{и} \mathrm{облучен-}$ ном массивах МУНТ, а также порошков кристаллических оксидов $\mathrm{SnO}$ и $\mathrm{SnO}_{2}$. Сравнение формы спектров композитов (рис. 3, кривые 1 и 2) со спектрами кристаллических оксидов олова (рис. 3, кривые 3 и 4 ) позволяет сделать однозначный вывод: в обоих композитах олово присутствует в виде оксида $\mathrm{SnO}$ с небольшим дефицитом по кислороду. На наличие кислородных вакансий в оксиде указывает присутствие в NEXAFS-спектрах композитов слабоинтенсивного максимума $\left(a_{1}\right)$, расположенного в районе энергий фотонов $\sim 487 \mathrm{eV}$ [9]. Наибольшую схожесть со спектром кристаллического $\mathrm{SnO}$ имеет спектр композита, сформированного на облученном массиве МУНТ (рис. 3, кривая 2), что указывает на достаточно высокую степень упорядоченности кристаллической структуры в этом композите $\mathrm{SnO}_{x}$ /МУНТ. В спектре композита, сформированного на исходном массиве МУНТ (рис. 3, кривая 1), наблюдается низкое соотношение сигнал-шум и слияние основных максимумов ( $a$ и $b, e$ и $f$ ). Это предположительно может быть обусловлено более развитым рельефом поверхности композита вследствие неравномерного распределения оксида олова по поверхности углеродных нанотрубок и наличия крупных металлооксидных глобул (см. рис. $1, a, b)$. Снижение тонкой структуры NEXAFS-спектра может также указывать на искажения кристаллической структуры оксида олова в композите, полученном на исходном массиве МУНТ.

Таким образом, проведенные исследования показали, что предварительное облучение массивов МУНТ ионами аргона при формировании композитов $\mathrm{SnO}_{x} / \mathrm{MУHТ}$ методом магнетронного распыления позволяет повысить адгезию оксида олова к стенкам углеродных нанотрубок. Ионная обработка обеспечивает формирование на поверхности МУНТ сплошных и одинаковых по толщине слоев оксида олова с однородной структурой. Предложенный в работе метод функционализации МУНТ может позволить получать композиты на основе углеродных нанотрубок и оксидов металлов с набором стабильных физико-химических характеристик.

\section{Благодарности}

Авторы благодарят сотрудников лаборатории синхротронного кольца BESSY II (Берлин, Германия) и руководство ОмЦКП СО РАН за предоставление оборудования и помощь при проведении исследований методами NEXAFS и СЭМ.

\section{Финансирование работы}

Работа выполнена в рамках государственного задания ОНЦ СО РАН в соответствии с Программой ФНИ ГАН на 2013-2020 гг. (номер госрегистрации проекта в системе ЕГИСУ НИОКТР АААА-А17-117041210227-8), а также при частичной финансовой поддержке гранта Пре- 
зидента РФ № МК-843.2019.8 и гранта Российского фонда фундаментальных исследований № 18-48-550009p_a.

\section{Конфликт интересов}

Авторы заявляют, что у них нет конфликта интересов.

\section{Список литературы}

[1] Camilli L., Passacantando M. // Chemosensors. 2018. V. 62. P. 1-17. DOI: $10.3390 /$ chemosensors 6040062

[2] Kim S.H., Lee J.Y., Yoon Y.S. // J. Alloys Compd. 2018. V. 742. P. 542-548. DOI: 10.1016/j.jallcom.2018.01.283

[3] Sahebian S., Zebarjad S.M., Khaki J.V., Lazzeri A. // Int. Nano Lett. 2016. V. 6. P. 183-190. DOI: 10.1007/s40089-016-0185-8

[4] Rahmandoust M., Ayatollahi M.R. // Adv. Struct. Mater. 2016. V. 39. P. 1-220. DOI: $10.1007 / 978-3-319-00251-4$

[5] Bobenko N.G., Bolotov V.V., Egorushkin V.E., Korusenko P.M., Melnikova N.V., Nesov S.N., Ponomarev A.N., Povoroznyuk S.N. // Carbon. 2019. V. 153. P. 40-51. DOI: 10.1016/j.carbon.2019.06.104

[6] Сивков В.Н., Объедков А.М., Петрова О.В., Некипелов С.В., Мингалева А.Е., Кремлев К.В., Каверин Б.С., Семенов Н.М., Кадомиева А.В., Гусев С.А., Юнин П.А., Татарский Д.А. // ФТТ. 2020. Т. 62. В. 1. С. 172-179. DOI: $10.21883 /$ FTT.2020.01.48756.315

[7] Nesov S.N., Korusenko P.M., Povoroznyuk S.N., Bolotov V.V., Knyazev E.V., Smirnov D.A. // Nucl. Instrum. Meth. Phys. Res. B. 2017. V. 410. P. 222-229. DOI: 10.1016/j.nimb.2017.08.040

[8] Чувенкова О.А., Домашевская Э.П., Рябцев С.В., Юраков Ю.А., Попов А.Е., Коюда Д.А., Нестеров Д.Н., Спирин Д.Е., Овсянников Р.Ю., Турищев С.Ю. // ФТТ. 2015. T. 57. B. 1. C. $145-152$.

[9] Manyakin M.D., Kurgansky S.I., Dubrovsky O.I., Chuvenkova O.A., Domashevskaya E.P., Ryabtsev S.V., Ovsyannikov R.Yu., Parinova E.V., Sivakov V., Turishchev S.Yu. // Mater. Sci. Semicond. Process. 2019. V. 99. P. 28-33. DOI: 10.1016/j.mssp.2019.04.006 